\title{
Penentuan Tingkat Kritikalitas Peralatan Pembangkit Dengan Metode Equipment Criticality Management Dalam Rangka Penentuan Prioritas Pemeliharaan
}

\author{
Saputra Dwi Nugroho \\ PT PLN (Persero) UPDL Suralaya, Indonesia \\ saputra.dn@pln.co.id
}

\begin{abstract}
The criticality level of equipment used at PT PLN (Pesero) power plants at present is using the Maintenance Priority Index (MPI) method. The calculation for the criticality rating of MPI equipment uses 4 (four) types of calculations, namely SCR, OCR, ACR and AFPF. To add to the consideration in determining the priority of equipment maintenance, an additional calculation of the criticality level of PLTU Tarahan equipment is carried out using the Equipment Criticality Management method. The Equipment Criticality Management method has 4 (four) assessment perspectives, namely Production, Safety, Environment and Equipment Failure. Calculations that have been carried out on the top 100 (one hundred) equipment in the PLTU Tarahan SERP using the Equipment Criticality Management method, there are 85 (eight five) equipment that has "High" criticality and 15 (fifteen) equipment in the "Medium" criticality category. 15 (fifteen) equipment that has "Medium" criticality is equipment that has backup and part of common generating equipment.
\end{abstract}

Keywords: Equipment, SERP, MPI, Equipment Criticality Management, Criticality Level

\begin{abstract}
ABSTRAK
Pemeringkatan tingkat kekritisan peralatan yang digunakan di pembangkit PT PLN (Pesero) saat ini adalah menggunakan metode Maintenance Priority Index (MPI). Perhitungan pemeringkatan kekritisan peralatan MPI menggunakan 4 (empat) jenis perhitungan yaitu SCR, OCR, ACR dan AFPF. Untuk menambah pertimbangan dalam penentutan prioritas pemeliharaan peralatan, dilakukan perhitungan tambahan tingkat kekritisan peralatan PLTU Tarahan menggunakan metode Equipment Criticality Management. Metode Equipment Criticality Management mempunyai 4 (empat) perspektif penilaian, yaitu Produksi, Keamanan, Lingkungan dan Kegagalan Peralatan. Perhitungan yang sudah dilakukan pada 100 (seratus) peralatan teratas yang ada dalam SERP PLTU Tarahan menggunakan metode Equipment Criticality Management, terdapat 85 (delapan lima) peralatan memiliki kritikalitas "High" dan 15 (lima belas) peralatan dalam kategori kritikalitas "Medium". 15 (lima belas) equipment yang memiliki kritikalitas "Medium" adalah equipment yang memiliki cadangan dan bagian dari peralatan common pembangkit.
\end{abstract}

Kata kunci: Peralatan, SERP, MPI, Equipment Criticality Management, Tingkat Kritikalitas 


\section{KILAT}

Vol. 10, No. 1, April 2021, P-ISSN 2089-1245, E-ISSN 2655-4925

DOI: https://doi.org/10.33322/kilat.v10i1.1178

\section{PENDAHULUAN}

PT PLN (Persero) adalah Badan Usaha Milik Negara (BUMN) yang bergerak pada bidang penyediaan energi listrik untuk masyarakat. PT PLN menjalankan bisnis kelistrikan dari mulai hulu atau pembangkit sampai dengan pendistribusian kepada masyarakan umum/industri.

Pada akhir Desember 2019, total kapasitas terpasang dan jumlah unit pembangkit PLN (Holding dan Anak Perusahaan) mencapai 43.856,58 MW dan 5.987 unit, dengan 30.368,23 MW (69,24\%) berada di Jawa. Total kapasitas terpasang mengalami peningkatan sebesar 5,18\% dibandingkan dengan akhir Desember 2018. Presentase kapasitas terpasang per jenis pembangkit sebagai berikut : PLTU 20.750,50 MW (47,31\%), PLTGU 10.708,76 MW (24,42\%), PLTD 3.692,38 MW (8,42\%), PLTMG 1.336,93 MW (3,05\%), PLTA 3.583,98 MW (8,17\%), PLTG 3.188,90 MW (7,27\%), PLTP 579,50 MW (1,32\%), PLT Surya dan PLT Bayu 15,62 MW (0,04\%). Adapun total kapasitas terpasang nasional termasuk pembangkit sewa dan IPP adalah 62.832,70 MW [1].

Pembangkit Listrik Tenaga Uap (PLTU) menjadi pembangkit yang prosentasenya paling besar diantara jenis pembangkit lain yang dimiliki oleh PLN. PT PLN (Persero) menerapkan manajemen aset pembangkit Enterprise Asset Managemen (EAM) dalam pengelolaan operasi dan pemeliharaan pembangkit dimulai pada tahun 2015 sebagaimana digunakan di dalam pembangkit lain untuk menjamin agar pembangkit selalu dalam kondisi handal (reliable). Asset Management memiliki peran yang sangat penting dalam sebuah pembangkit listrik. [2], [3]

Asset Management adalah istilah yang umum digunakan dalam bidang keuangan, real estate, gedung \& perkantoran, bidang alokasi sumber daya serta berbagai bidang lainya. Pada umumnya manajemen aset diartikan sebagai usaha memaksimalkan pemanfaatan dan tingakat pengambaglian aset dari sisi keuangan. Pada saat ini, istilah manajemen aset telah memulai diadopsi oleh industri proses, manufaktur, serta perusahaan peyedia jasa, untuk menjelaskan konsep pengelolaan aset fisik baik dari sisi pemanfaaatan, operasi, kinerja dan tingkat efektivitasnya [4].

Manajemen keandalan merupakan suatu kegiatan untuk menjamin tidak terjadinya suatu kegagalan pada seluruh komponen saat dioperasikan. Manajemen keandalan dapat meminimumkan biaya atau menghilangkan kegagalan dan penyebabnya. Berbagai gabungan jenis pemeliharaan pembangkit diharapkan dapat menjaga tersedianya suatu pembangkit dalam grid. Pemeliharaan harus dilakukan secara terus menerus untuk memastikan suatu produk dapat terus diandalkan. [5]-[8]

Tahapan proses dalam perencanaan pemeliharaan pembangkit, salah satu metodenya adalah dimulai dengan melakukan rangking terhadap tingkat kekritisan peralatan pembangkit (Maintenance Priority Index (MPI)) [9]. Pengetahuan tentang tingkat kekritisan suatu peralatan pembangkit akan sangat berguna, selain untuk pemeliharaan juga dapat bermanfaat untuk menjaga kelancaran pengoperasian [10]. Metode kebijakan pemeliharaan yang dilakukan berdasarkan risiko, metode pertama yang dilakukan adalah penetuan kritikalitas peralatan pembangkit [11], sehingga memang metode penentuan kritikalitas peralatan adalah langkah awal yang harus dilakukan untuk menentukan prioritas pemeliharaan.

Prioritisasi kritikalitas peralatan pembangkit yang sudah dilakukan, akan dilanjutkan dengan penentuan Failure Mode and Effect CriticalityAnalyzis (FMEA) [13], [14] dan pada akhirnya akan menjadi sebuah paket pekerjaan yang siap untuk direncanakan dan dieksekusi. Strategi pemeliharaan yang efektif melibatkan profesionalisme tingkat tinggi dalam hal pengambilan keputusan dalam hal waktu, tenaga kerja dan sumber daya lain yang dibutuhkan untuk pemeliharaan [12]. 
Unit usaha PLN yaitu PT PLN UPK Tarahan di provinsi Lampung, mengelola PLTU Batubara 2 x 100 MW dengan tipe Circulating Fluidized Bed (CFB). Metode perencanaan/penentuan strategi pemeliharaan di PLTU Tarahan menggunakan MPI sebagai dasar prioritisasi peralatan kritikal. Sebelum menghitung MPI, PLTU Tarahan membagi hirarki utama peralatan/aset pembangkit menjadi 2 (dua) yaitu System dan Equipment. Equipment adalah sub bagian dari sebuah system.

Dalam metode penentuan MPI PLTU Tarahan, penilaian kekritisan dibagi menjadi beberapa point penilaian yaitu :

a) Menentukan dampak kegagalan system terhadap operasi, biaya dan waktu pemeliharaan, safety, dan efisiensi pembangkit (System Critically Ranking (SCR)).

b) Menentukan dampak kegagalan sebuah equipment terhadap kecepatan waktu kegagalan sistem induk di atasnya (system) (Operational Critically Ranking (OCR)).

c) Mengkombinasikan Operational Criticality dengan System Criticality yang akan menghasilkan sebuah ranking dari satu peralatan berdasarkan tingkat kekritisannya terhadap operasi unit, yang disebut Asset Criticality Ranking (ACR). ACR = SCR x OCR. (II.5)

d) Menentukan Asset Failure Probability Factor (AFPF) yang menunjukkan tingkat kehandalan suatu peralatan dengan parameter yang diukur berupa frekuensi kerusakan dari peralatan tersebut dalam periode satu tahun terakhir.

e) Nilai MPI didapat dengan mengkombinasikan nilai ACR dan nilai AFPF. MPI = ACR x AFPF

Penelitian ini bertujuan untuk menambahkan tingkat kritikalitas peralatan pada SERP (System Equipment Reliability Prioritization) PLTU Tarahan dengan Metode Equipment Criticality Management dalam Operational Performance Improvement (OPI) [15].

\section{METODE PENELITIAN}

Metode penelitian yang dilakukan adalah pengambilan data 100 (seratus) equipment teratas pada SERP/Maintenance Priority Index (MPI) PLTU Tarahan tahun 2020, kemudian 100 (seratus) equipment tersebut dilakukan penambahan perhitungan menggunakan metode Equipment Criticality Management untuk mengetahui apakah equipment tersebut masuk kategori "Paling Kritis", "Kritis" atau "Non Prioritas".

\subsection{Pengolahan Data}

Metode equipment criticality management memiliki 4 (empat) perspektif penilaian yaitu : Produksi (Production), Keamanan (Safety), Lingkungan (Environment) dan Kerusakan Peralatan (Equipment Damage). 4 (empat) metode tersebut dijelaskan sebagai berikut :

1) Matriks Kritikalitas dari Perspektif Produksi (Production):

Metode ini memberikan matriks penilaian dari nilai $1-25$ yang dinilai berdasarkan probabilitas frekuensi loss of function/failure peralatan dengan konsekuensi yang terjadi terhadap produksi dan biaya finansial. 


\section{KILAT}

Vol. 10, No. 1, April 2021, P-ISSN 2089-1245, E-ISSN 2655-4925

DOI: https://doi.org/10.33322/kilat.v10i1.1178

\begin{tabular}{|c|c|c|c|c|c|}
\hline $\begin{array}{l}\text { Loss of function/failure merupakan kejadian biasa dan } \\
\text { berulang.'Sering' - rata-rata } 1 \text { kali per } 6-12 \text { bulan } \\
\text { Loss of function/failure merupakan kejadian biasa dan } \\
\text { berulang.'Sering' - rata-rata } 1 \text { kali per } 6-12 \text { bulan }\end{array}$ & 11 & 7 & 4 & 2 & 1 \\
\hline $\begin{array}{l}\text { Loss of function/failure diketahui terjadi, 'telah terjadi'. 'Kadang- } \\
\text { kadang' - rata-rata } 1 \text { kali per 2-3 tahun }\end{array}$ & 16 & 13 & 8 & 6 & 3 \\
\hline $\begin{array}{l}\text { Loss of function/failure dapat terjadi; 'Saya dengar telah terjadi' } \\
\text { di site ini atau lainnya.' Tidak Sering' - rata-rata } 1 \text { per 5-10 tahun }\end{array}$ & 20 & 17 & 14 & 9 & 5 \\
\hline $\begin{array}{l}\text { Loss of function/failure tidak mungkin terjadi.'Jarang' - rata-rata } \\
1 \text { kali dalam } 25 \text { tahun }\end{array}$ & 23 & 21 & 18 & 15 & 10 \\
\hline $\begin{array}{l}\text { Loss of function/failure praktis tidak mungkin terjadi.'Sangat } \\
\text { Jarang' - rata-rata } 1 \text { kali dalam } 100 \text { tahun }\end{array}$ & 25 & 24 & 22 & 19 & 12 \\
\hline \multirow[t]{2}{*}{ Probabilitas } & \begin{tabular}{|l} 
Loss of production \\
melalui kondisi unit, \\
biaya finansial $<\$ 10 \mathrm{~K}$
\end{tabular} & $\begin{array}{l}\text { Beberapa kerusakan } \\
\text { peralatan atau } \\
\text { shutdown, biaya } \\
\text { finansial }<\$ 100 \mathrm{~K}\end{array}$ & \begin{tabular}{|l|} 
Shutdown atau \\
kerusakan pada \\
peralatan, beberapa \\
kerusakan peralatan, \\
biaya finansial $<\$ 1 \mathrm{M}$
\end{tabular} & $\begin{array}{l}\text { Kerusakan banyak unit, } \\
\text { atau shutdown, biaya } \\
\text { finansial tinggi <\$10M }\end{array}$ & $\begin{array}{l}\text { Shutdown Refinery atau } \\
\text { bisnis, kerusakan } \\
\text { banyak unit, biaya } \\
\text { finansial sangat tinggi } \\
>\$ 10 M\end{array}$ \\
\hline & $\mathrm{E}$ & D & C & B & A \\
\hline
\end{tabular}

Gambar 1. Matriks Kritikalitas dari perspektif produksi

2) Matriks Kritikalitas dari Perspektif Keamanan (Safety)

Metode ini memberikan matriks penilaian dari nilai $1-25$ yang dinilai berdasarkan probabilitas cedera yang ditimbulkan peralatan dengan konsekuensi yang terjadi terhadap dampak cedera dan biaya finansialnya.

\begin{tabular}{|c|c|c|c|c|c|}
\hline $\begin{array}{l}\text { Cedera merupakan kejadian umum atau } \\
\text { berulang.'Sering' }\end{array}$ & 11 & 7 & 4 & 2 & 1 \\
\hline Cedera diketahui telah terjadi, 'telah terjadi'.'Occasional' & 16 & 13 & 8 & 6 & 3 \\
\hline $\begin{array}{l}\text { Cedera dapat terjadi; 'Saya dengar hal itu terjadi' di site } \\
\text { ini atau lainnya.'Tidak Sering' }\end{array}$ & 20 & 17 & 14 & 9 & 5 \\
\hline Cedera tidak mungkin terjadi.'Jarang' & 23 & 21 & 18 & 15 & 10 \\
\hline Cedera praktis tidak mungkin terjadi 'Sangat Jarang' & 25 & 24 & 22 & 19 & 12 \\
\hline \multirow[t]{2}{*}{ Probabilitas } & $\begin{array}{l}\text { Perawatan medis } \\
\text { terhadap cedera, } \\
\text { kondisi mendis } \\
\text { sementara, Cedera yang } \\
\text { dapat diatasi, biaya } \\
\text { finansial }<\$ 10 \mathrm{~K}\end{array}$ & $\begin{array}{l}\text { Cedera serius, cedera } \\
\text { cacat permanen, cedera } \\
\text { jangka panjang, biaya } \\
\text { finansial }<\$ 100 \mathrm{~K}\end{array}$ & $\begin{array}{l}\text { Fatality atau cacat } \\
\text { permanen, biaya } \\
\text { finansial }<\$ 1 M\end{array}$ & \begin{tabular}{|l} 
Berbagai fatality \\
internal, dampak \\
kesehatan permanen, \\
biaya finansial $<\$ 10 M$
\end{tabular} & $\begin{array}{l}\text { Berbagai fatality } \\
\text { internal dan eksternal, } \\
\text { keracunan akut atau } \\
\text { kronis, biaya finansial } \\
>\$ 10 \mathrm{M}\end{array}$ \\
\hline & $\mathrm{E}$ & D & C & B & A \\
\hline
\end{tabular}

Gambar 2. Matriks Kritikalitas dari Perspektif Keamanan

3) Matriks Kritikalitas dari perspektif lingkungan (Environment)

Metode ini memberikan matriks penilaian dari nilai $1-25$ yang dinilai berdasarkan probabilitas kerusakan lingkungan yang ditimbulkan peralatan dengan konsekuensi yang terjadi terhadap dampak kerusakan lingkungan dan biaya finansial. 


\begin{tabular}{|c|c|c|c|c|c|}
\hline \begin{tabular}{|l|} 
Kerusakan lingkungan adalah kejadian umum dan \\
berulang.'Sering' - rata-rata 1 kali per $6-12$ bulan
\end{tabular} & 11 & 7 & 4 & 2 & 1 \\
\hline \begin{tabular}{|l}
$\begin{array}{l}\text { Kerusakan lingkungan diketahui akan terjadi, 'telah } \\
\text { terjadi'. 'Occasional' - rata-rata } 1 \text { kali per 2-3 tahun }\end{array}$ \\
\end{tabular} & 16 & 13 & 8 & 6 & 3 \\
\hline $\begin{array}{l}\text { Kerusakan lingkungan dapat terjadi; 'Saya dengar terjadi' } \\
\text { di site ini atau lainnya.'Tidak Sering' - rata-rata } 1 \text { kali per } \\
\text { 5-10 tahun }\end{array}$ & 20 & 17 & 14 & 9 & 5 \\
\hline $\begin{array}{l}\text { Kerusakan lingkungan tidak mungkin terjadi.'Jarang' - } \\
\text { rata-rata } 1 \text { kali dalam } 25 \text { tahun }\end{array}$ & 23 & 21 & 18 & 15 & 10 \\
\hline \begin{tabular}{|l|} 
Kerusakan lingkungan praktis tidak mungkin terjadi \\
'Sangat Jarang' - rata-rata 1 kali dalam 100 tahun \\
\end{tabular} & 25 & 24 & 22 & 19 & 12 \\
\hline \multirow[t]{2}{*}{ c } & \begin{tabular}{|l|} 
Pelanggaran izin \\
lingkungan, masalah \\
minor yang tidak perlu \\
berulang, biaya $<\$ 10 \mathrm{~K}$
\end{tabular} & $\begin{array}{l}\text { Gangguan lingkungan } \\
\text { (Lama), pembuangan } \\
\text { pencemaran (Lama), } \\
\text { menempatkan } \\
\text { kontaminan yang dapat } \\
\text { menyebabkan } \\
\text { kerusakan atau } \\
\text { gangguan (Lama), } \\
\text { beberapa protes dari } \\
\text { masyarakat, }<\$ 100 K\end{array}$ & \begin{tabular}{|l|} 
Bahan berbahaya atau \\
dapat dengan sengja \\
membahayakan \\
lingkungan (Lama), \\
klaim kerusakan Pihak \\
Ketiga, protes \\
masyarakat terorganisir, \\
biaya <\$1M
\end{tabular} & \begin{tabular}{|l|} 
Kerusakan lingkungan \\
signifikan, permasalahan \\
serius publik, gagal \\
menerapkan EMP, protes \\
massa dan liputan media, \\
biaya finansial <\$10M
\end{tabular} & $\begin{array}{l}\text { Kerusakan lingkungan } \\
\text { tetap, klaim kerusakan } \\
\text { besar dari pihak ketig, } \\
\text { penempatan lahan luas } \\
\text { atau tumpahan minyak } \\
\text { ke laut, kemarahan } \\
\text { publik biaya finansial } \\
>\$ 10 M\end{array}$ \\
\hline & $E$ & D & C & B & $\mathbf{A}$ \\
\hline
\end{tabular}

Gambar 3. Matriks Kritikalitas dari perspektif lingkungan

4) Matriks Kritikalitas dari perspektif kerusakan peralatan (Equipement Damage)

Metode ini memberikan matriks penilaian dari nilai $1-25$ yang dinilai berdasarkan probabilitas frekuensi kerusakan peralatan dengan konsekuensi yang terjadi terhadap dampak kerusakan tersebut terhadap peralatan lain/unit dan biaya finansial.

\begin{tabular}{|c|c|c|c|c|c|}
\hline \begin{tabular}{|l|} 
Kerusakan peralatan adalah kejadian umum dan \\
berulang.'Sering' - rata-rata 1 kali per $6-12$ bulan \\
\end{tabular} & 11 & 7 & 4 & 2 & 1 \\
\hline $\begin{array}{l}\text { Kerusakan peralatan diketahui telah terjadi, 'telah } \\
\text { terjadi'. 'Occasional' - rata-rata } 1 \text { kali per 2-3 tahun } \\
\end{array}$ & 16 & 13 & 8 & 6 & 3 \\
\hline $\begin{array}{l}\text { Kerusakan peralatan tidak mungkin terjadi.'Jarang' - rata- } \\
\text { rata } 1 \text { kali dalam } 25 \text { tahun }\end{array}$ & 23 & 21 & 18 & 15 & 10 \\
\hline Konsekuensi & $\begin{array}{l}\text { Kerusakan peralatan } \\
\text { minor, waktu perbaikan } \\
\text { normal yand diterima, } \\
\text { biaya finansial }<\$ 10 \mathrm{~K}\end{array}$ & $\begin{array}{l}\text { Beberapa kerusakan } \\
\text { peralatan, waktu } \\
\text { perbaikan lebih panjang } \\
\text { daripada normal (mis: 2- } \\
3 \text { bulan), biaya finansial } \\
<\$ 100 \mathrm{~K}\end{array}$ & $\begin{array}{l}\text { Shutdown unit atau } \\
\text { kerusakan peralatan, } \\
\text { beberapa kerusakan } \\
\text { peralatan kritis, biaya } \\
\text { finansial }<\$ 1 \mathrm{M}\end{array}$ & $\begin{array}{l}\text { Kerusakan atau shutdown } \\
\text { banyak unit, biaya } \\
\text { finansial }<\$ 10 \mathrm{M}\end{array}$ & $\begin{array}{l}\text { Shutdown refinery atau } \\
\text { bisnis, kerusakan } \\
\text { banyak unit, biaya } \\
\text { finansial }>\$ 10 \mathrm{M}\end{array}$ \\
\hline
\end{tabular}

Gambar 4. Matriks Kritikalitas dari perspektif kerusakan peralatan

5) Penentuan tingkat kritikalitas peralatan

Penentuan kritikalitas dibagi menjadi 3 kategori yaitu :

a) Skor $1-10:$ kategori " $H$ " atau "Paling Kritis"

b) Skor $11-20:$ katergori "M" atau "Kritis" dan

c) Skor 21 - 25 : katergori "L" atau "Non Prioritas"

Kategori kritikalitas ditentukan dengan nilai paling kecil salah satu dari 4(empat) matriks yang telah disebutkan di atas.

\section{HASIL PENELITIAN}

Dari perhitungan yang sudah dilakukan, didapatkan criticality equipment PLTU Tarahan adalah sebagai berikut : 
KILAT

Vol. 10, No. 1, April 2021, P-ISSN 2089-1245, E-ISSN 2655-4925

DOI: https://doi.org/10.33322/kilat.v10i1.1178

\begin{tabular}{|c|c|c|c|c|c|c|c|c|}
\hline No & Asset & Description & MPI & $\begin{array}{l}\text { Producti } \\
\text { on Loss }\end{array}$ & Safety & $\begin{array}{c}\text { Environm } \\
\text { ent }\end{array}$ & $\begin{array}{l}\text { Equipm } \\
\text { ent } \\
\text { Damage }\end{array}$ & Risk \\
\hline 1 & $\begin{array}{l}\text { TRHN-TU-30- } \\
\text { HHE10AF001 }\end{array}$ & TRHN TU 30 COAL FEEDER A & 698 & 7 & 23 & 25 & 7 & $\mathrm{H}$ \\
\hline 2 & $\begin{array}{l}\text { TRHN-TU-30- } \\
\text { HHE10AF002 }\end{array}$ & TRHN TU 30 COAL FEEDER B & 698 & 7 & 23 & 25 & 7 & $\mathrm{H}$ \\
\hline 3 & $\begin{array}{l}\text { TRHN-TU-30- } \\
\text { HHE10AF003 }\end{array}$ & TRHN TU 30 COAL FEEDER C & 698 & 7 & 23 & 25 & 7 & $\mathrm{H}$ \\
\hline 4 & $\begin{array}{l}\text { TRHN-TU-40- } \\
\text { MAA10AA002 }\end{array}$ & $\begin{array}{l}\text { TRHN TU } 40 \text { MAIN STEAM C } \\
\text { ONTROL VALVE }\end{array}$ & 698 & 4 & 23 & 25 & 4 & $\mathrm{H}$ \\
\hline 5 & $\begin{array}{l}\text { TRHN-TU-40- } \\
\text { HLB11AN002 }\end{array}$ & TRHN TU 40 PA FAN 4B & 697 & 7 & 23 & 25 & 7 & $\mathrm{H}$ \\
\hline 6 & $\begin{array}{l}\text { TRHN-TU-30- } \\
\text { HLB10AN001 }\end{array}$ & TRHN TU 30 FA BLOWER 3A & 539 & 7 & 23 & 25 & 7 & $\mathrm{H}$ \\
\hline 7 & $\begin{array}{l}\text { TRHN-TU-40- } \\
\text { HLB10AN002 }\end{array}$ & TRHN TU 40 FA BLOWER 4B & 539 & 7 & 23 & 25 & 7 & $\mathrm{H}$ \\
\hline 8 & $\begin{array}{l}\text { TRHN-TU-40- } \\
\text { HLB10GX001 }\end{array}$ & $\begin{array}{l}\text { TRHN TU } 40 \text { MOTOR FA BLO } \\
\text { WER A }\end{array}$ & 539 & 7 & 23 & 25 & 7 & $\mathrm{H}$ \\
\hline 9 & $\begin{array}{l}\text { TRHN-TU-30- } \\
\text { HBK10AC002 }\end{array}$ & $\begin{array}{l}\text { TRHN TU } 30 \text { WATER WALL T } \\
\text { UBE }\end{array}$ & 525 & 4 & 23 & 25 & 4 & $\mathrm{H}$ \\
\hline 10 & $\begin{array}{l}\text { TRHN-TU-40- } \\
\text { HBK10AC002 }\end{array}$ & $\begin{array}{l}\text { TRHN TU } 40 \text { WATER WALL T } \\
\text { UBE }\end{array}$ & 525 & 4 & 25 & 25 & 4 & $\mathrm{H}$ \\
\hline 11 & $\begin{array}{l}\text { TRHN-TU-30- } \\
\text { MAA10AK001 }\end{array}$ & $\begin{array}{l}\text { TRHN TU } 30 \text { TURBINE STATO } \\
\text { R }\end{array}$ & 523 & 4 & 25 & 25 & 4 & $\mathrm{H}$ \\
\hline 12 & $\begin{array}{l}\text { TRHN-TU-30- } \\
\text { MAA10AK002 }\end{array}$ & $\begin{array}{l}\text { TRHN TU } 30 \text { TURBINE ROTO } \\
\text { R }\end{array}$ & 523 & 4 & 23 & 25 & 4 & $\mathrm{H}$ \\
\hline 13 & $\begin{array}{l}\text { TRHN-TU-40- } \\
\text { HHE10AF001 }\end{array}$ & TRHN TU 40 COAL FEEDER A & 523 & 7 & 23 & 25 & 4 & $\mathrm{H}$ \\
\hline 14 & $\begin{array}{l}\text { TRHN-TU-40- } \\
\text { HHE10AF002 }\end{array}$ & TRHN TU 40 COAL FEEDER B & 523 & 7 & 23 & 25 & 7 & $\mathrm{H}$ \\
\hline 15 & $\begin{array}{l}\text { TRHN-TU-40- } \\
\text { HHE10AF003 }\end{array}$ & TRHN TU 40 COAL FEEDER C & 523 & 7 & 23 & 25 & 7 & $\mathrm{H}$ \\
\hline 16 & $\begin{array}{l}\text { TRHN-TU-40- } \\
\text { MAA10AK001 }\end{array}$ & $\begin{array}{l}\text { TRHN TU } 40 \text { TURBINE STATO } \\
\mathrm{R}\end{array}$ & 523 & 4 & 23 & 25 & 4 & $\mathrm{H}$ \\
\hline 17 & $\begin{array}{l}\text { TRHN-TU-40- } \\
\text { MAV10AP001 }\end{array}$ & $\begin{array}{l}\text { TRHN TU } 40 \text { A- } \\
\text { MAIN OIL PUMP }\end{array}$ & 501 & 4 & 23 & 25 & 4 & $\mathrm{H}$ \\
\hline 18 & $\begin{array}{l}\text { TRHN-TU-30- } \\
\text { LAE10AA001 }\end{array}$ & $\begin{array}{l}\text { TRHN TU } 30 \text { BLOCK VALVE S } \\
\text { H SPRAY WATER } 1\end{array}$ & 489 & 11 & 20 & 25 & 11 & $\mathrm{M}$ \\
\hline 19 & $\begin{array}{l}\text { TRHN-TU-30- } \\
\text { LAE10AA002 }\end{array}$ & $\begin{array}{l}\text { TRHN TU } 30 \text { \#1 SUPER HEATE } \\
\text { R SPRAY CV }\end{array}$ & 489 & 4 & 20 & 25 & 4 & $\mathrm{H}$ \\
\hline 20 & $\begin{array}{l}\text { TRHN-TU-30- } \\
\text { LAE10AA003 }\end{array}$ & $\begin{array}{l}\text { TRHN TU } 30 \text { SH SPRAY \#1 CO } \\
\text { NTROL VALVE }\end{array}$ & 489 & 4 & 20 & 25 & 4 & $\mathrm{H}$ \\
\hline 21 & $\begin{array}{l}\text { TRHN-TU-30- } \\
\text { LAE10AA004 }\end{array}$ & $\begin{array}{l}\text { TRHN TU } 30 \text { SH SPRAY \#2 CO } \\
\text { NTROL VALVE }\end{array}$ & 489 & 4 & 20 & 25 & 4 & $\mathrm{H}$ \\
\hline 22 & $\begin{array}{l}\text { TRHN-TU-30- } \\
\text { LAF10AA001 }\end{array}$ & $\begin{array}{l}\text { TRHN TU } 30 \text { SPRAY WATER } \\
\text { AUX STEAM CONTROL VAL } \\
\text { VE }\end{array}$ & 489 & 7 & 20 & 25 & 4 & $\mathrm{H}$ \\
\hline 23 & $\begin{array}{l}\text { TRHN-TU-30- } \\
\text { LAF10AA002 }\end{array}$ & $\begin{array}{l}\text { TRHN TU } 30 \text { SPRAYWATER A } \\
\text { UX STEAM DE- } \\
\text { SH TEMPERATUR CONTROL } \\
\text { VALVE }\end{array}$ & 489 & 7 & 20 & 25 & 4 & $\mathrm{H}$ \\
\hline 24 & $\begin{array}{l}\text { TRHN-TU-30- } \\
\text { LAF10AA003 }\end{array}$ & $\begin{array}{l}\text { TRHN TU } 30 \text { SPRAYWATER A } \\
\text { UX STEAM DE- } \\
\text { SH PRESSURE REGULATOR } \\
\text { VALVE }\end{array}$ & 489 & 7 & 20 & 25 & 4 & $\mathrm{H}$ \\
\hline
\end{tabular}


KILAT

Vol. 10, No. 1, April 2021, P-ISSN 2089-1245, E-ISSN 2655-4925

DOI: https://doi.org/10.33322/kilat.v10i1.1178

\begin{tabular}{|c|c|c|c|c|c|c|c|c|}
\hline 25 & $\begin{array}{l}\text { TRHN-TU-40- } \\
\text { LAF10AA001 }\end{array}$ & $\begin{array}{l}\text { TRHN TU } 40 \text { SPRAY WATER } \\
\text { AUX STEAM CONTROL VAL } \\
\text { VE }\end{array}$ & 489 & 7 & 20 & 25 & 4 & $\mathrm{H}$ \\
\hline 26 & $\begin{array}{l}\text { TRHN-TU-40- } \\
\text { LAF10AA002 }\end{array}$ & $\begin{array}{l}\text { TRHN TU } 40 \text { SPRAYWATER A } \\
\text { UX STEAM DE- } \\
\text { SH TEMPERATUR CONTROL } \\
\text { VALVE }\end{array}$ & 489 & 7 & 20 & 25 & 4 & $\mathrm{H}$ \\
\hline 27 & $\begin{array}{l}\text { TRHN-TU-40- } \\
\text { LAF10AA003 }\end{array}$ & $\begin{array}{l}\text { TRHN TU } 40 \text { SPRAYWATER A } \\
\text { UX STEAM DE- } \\
\text { SH PRESSURE REGULATOR } \\
\text { VALVE }\end{array}$ & 489 & 7 & 20 & 25 & 4 & $\mathrm{H}$ \\
\hline 28 & $\begin{array}{l}\text { TRHN-TU-30- } \\
\text { MAX10AN001 }\end{array}$ & $\begin{array}{l}\text { TRHN TU } 30 \text { CONTROL OIL R } \\
\text { ADIATOR }\end{array}$ & 465 & 11 & 23 & 25 & 7 & $\mathrm{H}$ \\
\hline 29 & $\begin{array}{l}\text { TRHN-TU-40- } \\
\text { MAX10AN001 }\end{array}$ & $\begin{array}{l}\text { TRHN TU } 40 \text { CONTROL OIL R } \\
\text { ADIATOR }\end{array}$ & 465 & 11 & 23 & 25 & 7 & $\mathrm{H}$ \\
\hline 30 & $\begin{array}{l}\text { TRHN-TU-30- } \\
\text { QEA11AT001 }\end{array}$ & $\begin{array}{l}\text { TRHN TU } 30 \text { A- } \\
\text { INSTRUMENT AIR DRYER }\end{array}$ & 462 & 11 & 23 & 25 & 11 & $\mathrm{M}$ \\
\hline 31 & $\begin{array}{l}\text { TRHN-TU-30- } \\
\text { QEA11AT002 } \\
\end{array}$ & $\begin{array}{l}\text { TRHN TU } 30 \text { B- } \\
\text { INSTRUMENT AIR DRYER }\end{array}$ & 462 & 11 & 23 & 25 & 11 & M \\
\hline 32 & $\begin{array}{l}\text { TRHN-TU-40- } \\
\text { QEA11AT001 } \\
\end{array}$ & $\begin{array}{l}\text { TRHN TU } 40 \text { A- } \\
\text { INSTRUMENT AIR DRYER }\end{array}$ & 462 & 11 & 23 & 25 & 11 & $\mathrm{M}$ \\
\hline 33 & $\begin{array}{l}\text { TRHN-TU-40- } \\
\text { QEA11AT002 }\end{array}$ & $\begin{array}{l}\text { TRHN TU } 40 \text { B- } \\
\text { INSTRUMENT AIR DRYER }\end{array}$ & 462 & 11 & 23 & 25 & 11 & $\mathrm{M}$ \\
\hline 34 & $\begin{array}{l}\text { TRHN-TU-30- } \\
\text { BAC10GH001 }\end{array}$ & $\begin{array}{l}\text { TRHN TU } 30 \text { GENERATOR CI } \\
\text { RCUIT BREAKER }\end{array}$ & 442 & 4 & 18 & 25 & 7 & $\mathrm{H}$ \\
\hline 35 & $\begin{array}{l}\text { TRHN-TU-40- } \\
\text { BAC10GH001 }\end{array}$ & $\begin{array}{l}\text { TRHN TU } 40 \text { GENERATOR CI } \\
\text { RCUIT BREAKER }\end{array}$ & 442 & 4 & 18 & 25 & 7 & $\mathrm{H}$ \\
\hline 36 & $\begin{array}{l}\text { TRHN-TU-00- } \\
\text { EBC10AK001 }\end{array}$ & \begin{tabular}{|l|} 
TRHN TU 00 CN- \\
11 COAL CRUSHER A
\end{tabular} & 438 & 7 & 21 & 25 & 11 & $\mathrm{H}$ \\
\hline 37 & $\begin{array}{l}\text { TRHN-TU-00- } \\
\text { EBC10AK002 }\end{array}$ & $\begin{array}{l}\text { TRHN TU } 00 \text { CN- } \\
21 \text { COAL CRUSHER B }\end{array}$ & 438 & 7 & 21 & 25 & 11 & $\mathrm{H}$ \\
\hline 38 & $\begin{array}{l}\text { TRHN-TU-00- } \\
\text { EBC10AT001 }\end{array}$ & $\begin{array}{l}\text { TRHN TU } 00 \text { VS- } \\
11 \text { PRIMARY VIBRATING SCR } \\
\text { EEN } \\
\end{array}$ & 438 & 11 & 23 & 25 & 11 & $\mathrm{M}$ \\
\hline 39 & $\begin{array}{l}\text { TRHN-TU-00- } \\
\text { EBC10AT002 }\end{array}$ & $\begin{array}{l}\text { TRHN TU } 00 \text { VS- } \\
12 \text { SECONDARY VIBRATING } \\
\text { SCREEN }\end{array}$ & 438 & 11 & 23 & 25 & 11 & $\mathrm{M}$ \\
\hline 40 & $\begin{array}{l}\text { TRHN-TU-00- } \\
\text { EBC10AT003 }\end{array}$ & $\begin{array}{l}\text { TRHN TU } 00 \text { VS- } \\
21 \text { PRIMARY VIBRATING SCR } \\
\text { EEN }\end{array}$ & 438 & 11 & 23 & 25 & 11 & $\mathrm{M}$ \\
\hline 41 & $\begin{array}{l}\text { TRHN-TU-00- } \\
\text { EBC10AT004 }\end{array}$ & $\begin{array}{l}\text { TRHN TU 00 VS- } \\
22 \text { SECONDARY VIBRATING } \\
\text { SCREEN }\end{array}$ & 438 & 11 & 23 & 25 & 11 & $\mathrm{M}$ \\
\hline 42 & $\begin{array}{l}\text { TRHN-TU-00- } \\
\text { EBC10AK003 }\end{array}$ & $\begin{array}{l}\text { TRHN TU 00 DC- } \\
\text { 05 DUST COLLECTOR }\end{array}$ & 438 & 11 & 23 & 25 & 11 & $\mathrm{M}$ \\
\hline 43 & $\begin{array}{l}\text { TRHN-TU-30- } \\
\text { HLB10AN002 }\end{array}$ & TRHN TU 30 FA BLOWER 3B & 404 & 7 & 23 & 25 & 11 & $\mathrm{H}$ \\
\hline 44 & $\begin{array}{l}\text { TRHN-TU-30- } \\
\text { HLB10GX001 }\end{array}$ & $\begin{array}{l}\text { TRHN TU } 30 \text { MOTOR FA BLO } \\
\text { WER A }\end{array}$ & 404 & 7 & 23 & 25 & 11 & $\mathrm{H}$ \\
\hline 45 & $\begin{array}{l}\text { TRHN-TU-30- } \\
\text { HLB10GX002 }\end{array}$ & $\begin{array}{l}\text { TRHN TU } 30 \text { MOTOR FA BLO } \\
\text { WER B }\end{array}$ & 404 & 7 & 23 & 25 & 11 & $\mathrm{H}$ \\
\hline 46 & $\begin{array}{l}\text { TRHN-TU-40- } \\
\text { HLB10AN001 }\end{array}$ & TRHN TU 40 FA BLOWER 4A & 404 & 7 & 23 & 25 & 11 & $\mathrm{H}$ \\
\hline 47 & $\begin{array}{l}\text { TRHN-TU-40- } \\
\text { HLB10GX002 }\end{array}$ & $\begin{array}{l}\text { TRHN TU } 40 \text { MOTOR FA BLO } \\
\text { WER B }\end{array}$ & 404 & 7 & 23 & 25 & 11 & $\mathrm{H}$ \\
\hline 48 & $\begin{array}{l}\text { TRHN-TU-40- } \\
\text { LAE10AA001 }\end{array}$ & $\begin{array}{l}\text { TRHN TU } 40 \text { BLOCK VALVE S } \\
\text { H SPRAY WATER } 1 \\
\end{array}$ & 396 & 11 & 23 & 25 & 11 & $\mathrm{M}$ \\
\hline
\end{tabular}




\section{KILAT}

Vol. 10, No. 1, April 2021, P-ISSN 2089-1245, E-ISSN 2655-4925

DOI: https://doi.org/10.33322/kilat.v10i1.1178

\begin{tabular}{|c|c|c|c|c|c|c|c|c|}
\hline 49 & $\begin{array}{l}\text { TRHN-TU-40- } \\
\text { LAE10AA002 }\end{array}$ & $\begin{array}{l}\text { TRHN TU } 40 \text { \#1 SUPER HEATE } \\
\text { R SPRAY CV }\end{array}$ & 396 & 4 & 23 & 25 & 7 & $\mathrm{H}$ \\
\hline 50 & $\begin{array}{l}\text { TRHN-TU-40- } \\
\text { LAE10AA003 }\end{array}$ & $\begin{array}{l}\text { TRHN TU } 40 \text { SH SPRAY \#1 CO } \\
\text { NTROL VALVE }\end{array}$ & 396 & 4 & 23 & 25 & 7 & $\mathrm{H}$ \\
\hline 51 & $\begin{array}{l}\text { TRHN-TU-40- } \\
\text { LAE10AA004 }\end{array}$ & $\begin{array}{l}\text { TRHN TU } 40 \text { SH SPRAY \#2 CO } \\
\text { NTROL VALVE }\end{array}$ & 396 & 4 & 23 & 25 & 7 & $\mathrm{H}$ \\
\hline 52 & $\begin{array}{l}\text { TRHN-TU-30- } \\
\text { PAA10AT001 }\end{array}$ & $\begin{array}{l}\text { TRHN TU } 30 \text { A- } \\
\text { INTAKE WATER SCREEN }\end{array}$ & 379 & 7 & 23 & 25 & 7 & $\mathrm{H}$ \\
\hline 53 & $\begin{array}{l}\text { TRHN-TU-30- } \\
\text { PAA10AT002 }\end{array}$ & $\begin{array}{l}\text { TRHN TU } 30 \text { B- } \\
\text { INTAKE WATER SCREEN }\end{array}$ & 379 & 7 & 23 & 25 & 7 & $\mathrm{H}$ \\
\hline 54 & $\begin{array}{l}\text { TRHN-TU-30- } \\
\text { PAA10EA001 }\end{array}$ & $\begin{array}{l}\text { TRHN TU } 30 \text { PLC INTAKE SC } \\
\text { REEN SYSTEM }\end{array}$ & 379 & & 23 & 25 & 7 & $\mathrm{H}$ \\
\hline 55 & $\begin{array}{l}\text { TRHN-TU-40- } \\
\text { PAA10AT001 }\end{array}$ & $\begin{array}{l}\text { TRHN TU } 40 \text { A- } \\
\text { INTAKE WATER SCREEN }\end{array}$ & 379 & 7 & 23 & 25 & 7 & $\mathrm{H}$ \\
\hline 56 & $\begin{array}{l}\text { TRHN-TU-40- } \\
\text { PAA10AT002 }\end{array}$ & $\begin{array}{l}\text { TRHN TU } 40 \text { B- } \\
\text { INTAKE WATER SCREEN }\end{array}$ & 379 & 7 & 23 & 25 & 7 & $\mathrm{H}$ \\
\hline 57 & $\begin{array}{l}\text { TRHN-TU-40- } \\
\text { PAA10EA001 }\end{array}$ & $\begin{array}{l}\text { TRHN TU } 40 \text { PLC INTAKE SC } \\
\text { REEN SYSTEM }\end{array}$ & 379 & 7 & 23 & 25 & 7 & $\mathrm{H}$ \\
\hline 58 & $\begin{array}{l}\text { TRHN-TU-30- } \\
\text { HDF10AK001 }\end{array}$ & TRHN TU 30 CYCLONE & 377 & 4 & 23 & 25 & 4 & $\mathrm{H}$ \\
\hline 59 & $\begin{array}{l}\text { TRHN-TU-30- } \\
\text { HDF10AK002 }\end{array}$ & TRHN TU 30 SEALPOT & 377 & 4 & 23 & 25 & 4 & $\mathrm{H}$ \\
\hline 60 & $\begin{array}{l}\text { TRHN-TU-30- } \\
\text { HDF10AT001 }\end{array}$ & $\begin{array}{l}\text { TRHN TU } 30 \text { VORTEX FINDE } \\
\mathrm{R}\end{array}$ & 377 & 4 & 23 & 25 & 7 & $\mathrm{H}$ \\
\hline 61 & $\begin{array}{l}\text { TRHN-TU-40- } \\
\text { HDF10AK001 }\end{array}$ & TRHN TU 40 CYCLONE & 377 & 4 & 23 & 25 & 4 & $\mathrm{H}$ \\
\hline 62 & $\begin{array}{l}\text { TRHN-TU-40- } \\
\text { HDF10AK002 }\end{array}$ & TRHN TU 40 SEALPOT & 377 & 4 & 23 & 25 & 4 & $\mathrm{H}$ \\
\hline 63 & $\begin{array}{l}\text { TRHN-TU-40- } \\
\text { HDF10AT001 }\end{array}$ & $\begin{array}{l}\text { TRHN TU } 40 \text { VORTEX FINDE } \\
\text { R }\end{array}$ & 377 & 4 & 23 & 25 & 7 & $\mathrm{H}$ \\
\hline 64 & $\begin{array}{l}\text { TRHN-TU-30- } \\
\text { LCB10AP001 }\end{array}$ & $\begin{array}{l}\text { TRHN TU } 30 \text { A- } \\
\text { CONDENSATE PUMP }\end{array}$ & 376 & 7 & 23 & 25 & 7 & $\mathrm{H}$ \\
\hline 65 & $\begin{array}{l}\text { TRHN-TU-30- } \\
\text { LCB10AP002 }\end{array}$ & $\begin{array}{l}\text { TRHN TU } 30 \text { B- } \\
\text { CONDENSATE PUMP }\end{array}$ & 376 & 7 & 23 & 25 & 7 & $\mathrm{H}$ \\
\hline 66 & $\begin{array}{l}\text { TRHN-TU-30- } \\
\text { LCB10GX001 }\end{array}$ & $\begin{array}{l}\text { TRHN TU } 30 \text { A- MOTOR CON } \\
\text { DENSATE PUMP }\end{array}$ & 376 & 7 & 23 & 25 & 7 & $\mathrm{H}$ \\
\hline 67 & $\begin{array}{l}\text { TRHN-TU-30- } \\
\text { LCB10GX002 }\end{array}$ & $\begin{array}{l}\text { TRHN TU } 30 \text { B- } \\
\text { MOTOR CONDENSATE PUMP }\end{array}$ & 376 & 7 & 23 & 25 & 7 & $\mathrm{H}$ \\
\hline 68 & $\begin{array}{l}\text { TRHN-TU-40- } \\
\text { LCB10AP001 }\end{array}$ & $\begin{array}{l}\text { TRHN TU } 40 \text { A- } \\
\text { CONDENSATE PUMP }\end{array}$ & 376 & 7 & 23 & 25 & 7 & $\mathrm{H}$ \\
\hline 69 & $\begin{array}{l}\text { TRHN-TU-40- } \\
\text { LCB10AP002 }\end{array}$ & $\begin{array}{l}\text { TRHN TU } 40 \text { B- } \\
\text { CONDENSATE PUMP }\end{array}$ & 376 & 7 & 23 & 25 & 7 & $\mathrm{H}$ \\
\hline 70 & $\begin{array}{l}\text { TRHN-TU-40- } \\
\text { LCB10GX001 }\end{array}$ & $\begin{array}{l}\text { TRHN TU } 40 \text { A- MOTOR CON } \\
\text { DENSATE PUMP }\end{array}$ & 376 & 7 & 23 & 25 & 7 & $\mathrm{H}$ \\
\hline 71 & $\begin{array}{l}\text { TRHN-TU-40- } \\
\text { LCB10GX002 }\end{array}$ & $\begin{array}{l}\text { TRHN TU } 40 \text { B- } \\
\text { MOTOR CONDENSATE PUMP }\end{array}$ & 376 & 7 & 23 & 25 & 7 & $\mathrm{H}$ \\
\hline 72 & $\begin{array}{l}\text { TRHN-TU-30- } \\
\text { MAX10AP001 }\end{array}$ & $\begin{array}{l}\text { TRHN TU } 30 \text { A- } \\
\text { CONTROL OIL PUMP }\end{array}$ & 372 & 7 & 23 & 25 & 7 & $\mathrm{H}$ \\
\hline 73 & $\begin{array}{l}\text { TRHN-TU-30- } \\
\text { MAX10AP002 }\end{array}$ & $\begin{array}{l}\text { TRHN TU } 30 \text { B- } \\
\text { CONTROL OIL PUMP }\end{array}$ & 372 & 7 & 23 & 25 & 7 & $\mathrm{H}$ \\
\hline 74 & $\begin{array}{l}\text { TRHN-TU-30- } \\
\text { MAX10GX001 }\end{array}$ & $\begin{array}{l}\text { TRHN TU } 30 \text { A- } \\
\text { MOTOR CONTROL OIL PUMP }\end{array}$ & 372 & 11 & 23 & 25 & 7 & $\mathrm{H}$ \\
\hline 75 & $\begin{array}{l}\text { TRHN-TU-30- } \\
\text { MAX10GX002 }\end{array}$ & $\begin{array}{l}\text { TRHN TU } 30 \text { B- } \\
\text { MOTOR CONTROL OIL PUMP }\end{array}$ & 372 & 11 & 23 & 25 & 7 & $\mathrm{H}$ \\
\hline 76 & $\begin{array}{l}\text { TRHN-TU-40- } \\
\text { MAX10AP001 }\end{array}$ & $\begin{array}{l}\text { TRHN TU } 40 \text { A- } \\
\text { CONTROL OIL PUMP }\end{array}$ & 372 & 11 & 23 & 25 & 7 & $\mathrm{H}$ \\
\hline
\end{tabular}


KILAT

Vol. 10, No. 1, April 2021, P-ISSN 2089-1245, E-ISSN 2655-4925

DOI: https://doi.org/10.33322/kilat.v10i1.1178

\begin{tabular}{|c|c|c|c|c|c|c|c|c|}
\hline 77 & $\begin{array}{l}\text { TRHN-TU-40- } \\
\text { MAX10AP002 }\end{array}$ & $\begin{array}{l}\text { TRHN TU } 40 \text { B- } \\
\text { CONTROL OIL PUMP }\end{array}$ & 372 & 11 & 23 & 25 & 7 & $\mathrm{H}$ \\
\hline 78 & $\begin{array}{l}\text { TRHN-TU-40- } \\
\text { MAX10GX001 }\end{array}$ & $\begin{array}{l}\text { TRHN TU } 40 \text { A- } \\
\text { MOTOR CONTROL OIL PUMP }\end{array}$ & 372 & 11 & 23 & 25 & 7 & $\mathrm{H}$ \\
\hline 79 & $\begin{array}{l}\text { TRHN-TU-40- } \\
\text { MAX10GX002 }\end{array}$ & $\begin{array}{l}\text { TRHN TU } 40 \text { B- } \\
\text { MOTOR CONTROL OIL PUMP }\end{array}$ & 372 & 11 & 23 & 25 & 7 & $\mathrm{H}$ \\
\hline 80 & $\begin{array}{l}\text { TRHN-TU-30- } \\
\text { QEA11AN001 }\end{array}$ & $\begin{array}{l}\text { TRHN TU } 30 \text { A- } \\
\text { INSTRUMENT AIR COMPRES } \\
\text { SOR }\end{array}$ & 369 & 7 & 23 & 25 & 11 & M \\
\hline 81 & $\begin{array}{l}\text { TRHN-TU-30- } \\
\text { QEA11AN002 }\end{array}$ & $\begin{array}{l}\text { TRHN TU } 30 \text { B- } \\
\text { INSTRUMENT AIR COMPRES } \\
\text { SOR }\end{array}$ & 369 & 7 & 23 & 25 & 11 & M \\
\hline 82 & $\begin{array}{l}\text { TRHN-TU-40- } \\
\text { QEA11AN001 }\end{array}$ & $\begin{array}{l}\text { TRHN TU } 40 \text { A- } \\
\text { INSTRUMENT AIR COMPRES } \\
\text { SOR }\end{array}$ & 369 & 7 & 23 & 25 & 11 & M \\
\hline 83 & $\begin{array}{l}\text { TRHN-TU-40- } \\
\text { QEA11AN002 }\end{array}$ & $\begin{array}{l}\text { TRHN TU } 40 \text { B- } \\
\text { INSTRUMENT AIR COMPRES } \\
\text { SOR }\end{array}$ & 369 & 7 & 23 & 25 & 11 & M \\
\hline 84 & $\begin{array}{l}\text { TRHN-TU-00- } \\
\text { GCF10AA001 }\end{array}$ & $\begin{array}{l}\text { TRHN TU 00 MIXED BED A AI } \\
\text { R RELEASE VALVE (VENTIN } \\
\text { G) - AA001 }\end{array}$ & 355 & 11 & 23 & 25 & 7 & $\mathrm{H}$ \\
\hline 85 & $\begin{array}{l}\text { TRHN-TU-00- } \\
\text { GCF10AA002 }\end{array}$ & $\begin{array}{l}\text { TRHN TU 00 MIXED BED A S } \\
\text { ERVICE INLET VALVE - AA00 } \\
4\end{array}$ & 355 & 11 & 23 & 25 & 7 & $\mathrm{H}$ \\
\hline 86 & $\begin{array}{l}\text { TRHN-TU-00- } \\
\text { GCF10AA003 }\end{array}$ & $\begin{array}{l}\text { TRHN TU } 00 \text { MIXED BED A S } \\
\text { ERVICE OUTLET VALVE - AA } \\
005\end{array}$ & 355 & 11 & 23 & 25 & 7 & $\mathrm{H}$ \\
\hline 87 & $\begin{array}{l}\text { TRHN-TU-00- } \\
\text { GCF10AA004 }\end{array}$ & $\begin{array}{l}\text { TRHN TU 00 MIXED BED A B } \\
\text { ACKWASH INLET/INLET CA } \\
\text { USTIC SLOW RINCE VALVE - } \\
\text { AA006 }\end{array}$ & 355 & 11 & 23 & 25 & 7 & $\mathrm{H}$ \\
\hline 88 & $\begin{array}{l}\text { TRHN-TU-00- } \\
\text { GCF10AA005 }\end{array}$ & $\begin{array}{l}\text { TRHN TU 00 MIXED BED A B } \\
\text { ACKWASH OUTLET VALVE - } \\
\text { AA007 }\end{array}$ & 355 & 11 & 23 & 25 & 7 & $\mathrm{H}$ \\
\hline 89 & $\begin{array}{l}\text { TRHN-TU-00- } \\
\text { GCF10AA006 }\end{array}$ & $\begin{array}{l}\text { TRHN TU } 00 \text { MIXED BED A M } \\
\text { IDDLE COLLECTOR INLET V } \\
\text { ALVE - AA008 }\end{array}$ & 355 & 11 & 23 & 25 & 7 & $\mathrm{H}$ \\
\hline 90 & $\begin{array}{l}\text { TRHN-TU-00- } \\
\text { GCF10AA007 }\end{array}$ & $\begin{array}{l}\text { TRHN TU 00 MIXED BED A C } \\
\text { AUSTIC SLOW RINCE OUTLE } \\
\text { T VALVE - AA009 }\end{array}$ & 355 & 11 & 23 & 25 & 7 & $\mathrm{H}$ \\
\hline 91 & $\begin{array}{l}\text { TRHN-TU-00- } \\
\text { GCF10AA008 }\end{array}$ & $\begin{array}{l}\text { TRHN TU 00 MIXED BED A M } \\
\text { IDDLE COLLECTOR OUTLET } \\
\text { VALVE - AA010 }\end{array}$ & 355 & 11 & 23 & 25 & 7 & $\mathrm{H}$ \\
\hline 92 & $\begin{array}{l}\text { TRHN-TU-00- } \\
\text { GCF10AA009 }\end{array}$ & $\begin{array}{l}\text { TRHN TU } 00 \text { MIXED BED A B } \\
\text { LOWER AIR INLET VALVE - } \\
\text { AA011 }\end{array}$ & 355 & 11 & 23 & 25 & 7 & $\mathrm{H}$ \\
\hline 93 & $\begin{array}{l}\text { TRHN-TU-00- } \\
\text { GCF10AA010 }\end{array}$ & $\begin{array}{l}\text { TRHN TU 00 MIXED BED B AI } \\
\text { R RELEASE VALVE (VENTIN } \\
\text { G) - AA001 }\end{array}$ & 355 & 11 & 23 & 25 & 7 & $\mathrm{H}$ \\
\hline 94 & $\begin{array}{l}\text { TRHN-TU-00- } \\
\text { GCF10AA011 }\end{array}$ & $\begin{array}{l}\text { TRHN TU 00 MIXED BED B SE } \\
\text { RVICE INLET VALVE - AA004 }\end{array}$ & 355 & 11 & 23 & 25 & 7 & $\mathrm{H}$ \\
\hline 95 & $\begin{array}{l}\text { TRHN-TU-00- } \\
\text { GCF10AA012 }\end{array}$ & $\begin{array}{l}\text { TRHN TU } 00 \text { MIXED BED B SE } \\
\text { RVICE OUTLET VALVE - AA0 } \\
05\end{array}$ & 355 & 11 & 23 & 25 & 7 & $\mathrm{H}$ \\
\hline 96 & $\begin{array}{l}\text { TRHN-TU-00- } \\
\text { GCF10AA013 }\end{array}$ & $\begin{array}{l}\text { TRHN TU } 00 \text { MIXED BED B B } \\
\text { ACKWASH INLET/INLET CA }\end{array}$ & 355 & 11 & 23 & 25 & 7 & $\mathrm{H}$ \\
\hline
\end{tabular}




\section{KILAT}

Vol. 10, No. 1, April 2021, P-ISSN 2089-1245, E-ISSN 2655-4925

DOI: https://doi.org/10.33322/kilat.v10i1.1178

\begin{tabular}{|c|l|l|c|c|c|c|c|} 
& & $\begin{array}{l}\text { USTIC SLOW RINCE VALVE - } \\
\text { AA006 }\end{array}$ & & & \\
\hline 97 & $\begin{array}{l}\text { TRHN-TU-00- } \\
\text { GCF10AA014 }\end{array}$ & $\begin{array}{l}\text { TRHN TU 00 MIXED BED B B } \\
\text { ACKWASH OUTLET VALVE - } \\
\text { AA007 }\end{array}$ & 355 & 11 & 23 & 25 & 7 \\
\hline 98 & $\begin{array}{l}\text { TRHN-TU-00- } \\
\text { GCF10AA015 }\end{array}$ & $\begin{array}{l}\text { TRHN TU 00 MIXED BED B M } \\
\text { IDDLE COLLECTOR INLET V } \\
\text { ALVE - AA008 }\end{array}$ & 355 & 11 & 23 & 25 & 7 \\
\hline 99 & $\begin{array}{l}\text { TRHN-TU-00- } \\
\text { GCF10AA016 }\end{array}$ & $\begin{array}{l}\text { TRHN TU 00 MIXED BED B C } \\
\text { AUSTIC SLOW RINCE OUTLE } \\
\text { T VALVE - AA009 }\end{array}$ & 355 & 11 & 23 & 25 & 7 \\
\hline 100 & $\begin{array}{l}\text { TRHN-TU-00- } \\
\text { GCF10AA017 }\end{array}$ & $\begin{array}{l}\text { TRHN TU 00 MIXED BED B M } \\
\text { IDDLE COLLECTOR OUTLET } \\
\text { VALVE - AA010 }\end{array}$ & 355 & 11 & 23 & 25 & H \\
\hline
\end{tabular}

\section{KESIMPULAN DAN SARAN}

Hasil perhitungan Equipment Criticality Management didapatkan 100 (seratus) equiment MPI teratas PLTU Tarahan yang menjadi sampel, terdapat 85 (delapan lima) equipment memiliki kritikalitas "H" atau "Paling Kritis" dan 15 (lima belas) equipment dalam katogori kritikalitas "M" atau "Kritis". 15 (lima belas) equipment yang memiliki kritikalitas " $\mathrm{M}$ " atau "Kritis" adalah equipment yang memiliki cadangan/redundant dan bagian dari equipment common pembangkit.

Prioritas pemeliharaan peralatan di PLTU Tarahan dapat dilakukan terlebih dahulu untuk kategori peralatan dengan kategori " $\mathrm{H}$ " atau "Paling Kritis", kemudian setelahnya dilanjutkan pemeliharaan untuk peralatan kategori "M" atau "Kritis".

\section{UCAPAN TERIMA KASIH}

Penulis mengucapkan terima kasih kepada PT PLN (Persero) UIKSBS UPK Tarahan dan STTPLN yang telah memberi dukungan yang membantu pelaksanaan penelitian hingga terwujud.

\section{DAFTAR PUSTAKA}

[1] PT PLN (Persero), “Statistik PLN 2019," Jakarta, 2019.

[2] L. Li and J. H. Qu, "Design and realization of enterprise assets management system in power plants," Dianli Xitong Zidonghua/Automation Electr. Power Syst., vol. 29, no. 13, 2005.

[3] N. Fujisawa, S. Matsuo, Y. Yamamoto, and K. Nonaka, "Thermal power plant asset management with asset-centric data model," Fujitsu Sci. Tech. J., vol. 50, no. 2, 2014.

[4] J. S. Mitchell, Pyshical Asset Managemen Handbook, 4th ed. Jakarta: MTS Indonesia, 2006.

[5] E. Hartini, S. Dibyo, and S. Pujiarta, "Determination of Maintenance Priority Index (Mpi) for Components on Rsg-Gas Safety System,” J. Teknol. Reakt. Nukl. Tri Dasa Mega, vol. 20, no. 2, p. 77, 2018, doi: 10.17146/tdm.2018.20.2.4283.

[6] M. BULUT and E. ÖZCAN, "A new approach to determine maintenance periods of the most critical hydroelectric power plant equipment," Reliab. Eng. Syst. Saf., vol. 205, 2021, doi: 10.1016/j.ress.2020.107238.

[7] A. Silvestri, C. Cerbaso, D. Falcone, A. Forcina, and V. Duraccio, "Maintenance critical analysis and priority index: A new model for maintenance policy," 26th Eur. Model. Simul. Symp. EMSS 2014, no. September, pp. 432-437, 2014.

[8] P. Velayutham and F. B. Ismail, "A Review on Power Plant Maintenance and Operational 
Performance," in MATEC Web of Conferences, Nov. 2018, vol. 225, doi: 10.1051/matecconf/201822505003.

[9] EPRI, "Guideline on Proactive Maintenance," p. 77, 2001.

[10] H. Sabouhi, A. Abbaspour, M. Fotuhi-Firuzabad, and P. Dehghanian, "Reliability modeling and availability analysis of combined cycle power plants," Int. J. Electr. Power Energy Syst., vol. 79, pp. 108-119, Jul. 2016, doi: 10.1016/j.ijepes.2016.01.007.

[11] F. G. Carazas and G. F. M. Souza, "Risk-based decision making method for maintenance policy selection of thermal power plant equipment," Energy, vol. 35, no. 2, pp. 964-975, 2010, doi: 10.1016/j.energy.2009.06.054.

[12] A. Pai and S. Rane, "Development and implementation of maintenance management module of enterprise resource planning in maintenance of power plant," Int. J. Syst. Assur. Eng. Manag., vol. 5, no. 4, pp. 534-543, Dec. 2014, doi: 10.1007/s13198-013-0203-4.

[13] A. H. A. Melani, C. A. Murad, A. Caminada Netto, G. F. M. de Souza, and S. I. Nabeta, "Criticality-based maintenance of a coal-fired power plant," Energy, vol. 147, pp. 767-781, Mar. 2018, doi: 10.1016/j.energy.2018.01.048.

[14] J. Mobray, Reliability Center Maintenance, Second. New York: PT Relogica Indonesia, 2011.

[15] PT PLN (Persero), “Equipment Critically Management - OPI,” Bogor, 2010. 